\title{
Bacurau, desertos de notícias e a comunicação popular
}

Danielle Marcia Hachmann de Lacerda da Gama ${ }^{1}$

\section{Resumo}

Este trabalho é um artigo de opinião que busca realizar uma reflexão sobre a comunicação popular a partir do longa-metragem brasileiro Bacurau (2019). O filme de ficção, dirigido por Kleber Mendonça Filho e Juliano Dornelles, traz como cena e cenário uma cidade no sertão do nordeste, chamada Bacurau, que se vê atacada por invasores estrangeiros que cometem assassinatos por divertimento. A narrativa nos apresenta a população dessa pequena cidade desprezada pelos seus governantes, que defende a si mesma dos ataques deles e dos estrangeiros. Para isso fazem uso de instrumentos e processos comunicativos que podem ser considerados dentro das ações de comunicação popular.

\section{Palavras-chave}

Bacurau. Comunicação Popular. Cinema brasileiro.

1 Mestra em Ciências Sociais pela Universidade Federal do Recôncavo da Bahia, Brasil. E-mail: dani.dagama@hotmail.com. 


\title{
Bacurau, news desert and the popular communication
}

Danielle Marcia Hachmann de Lacerda da Gama²

\begin{abstract}
The present work is an opinion piece that aims to launch a reflection about popular communication departing from the Brazilian feature film Bacurau (2019). The fictional work, directed by Kleber Mendonça Filho and Juliano Dornelles, brings as scene and scenario a city in northeast hinterland, named Bacurau, which finds itself attacked by foreign invaders who commit murders for fun. The narrative presents us the population of this small city, disregarded by its governors, that defends itself from their attacks and the foreigners' as well. For that, they use communicative devices and processes that can be considered as actions of popular communication.
\end{abstract}

\section{Keywords}

Bacurau. Popular Communication. Brasilian cinema.

${ }^{2}$ Master in Social Sciences, Federal University of Recôncavo da Bahia, State of Bahia, Brazil. E-mail: dani.dagama@hotmail.com. 
Levei algum tempo para conseguir assistir Bacurau ${ }^{3}$, que entrou em cartaz nos cinemas em fins de agosto de 2019: estive nos últimos meses em uma cidade no interior de Santa Catarina, onde o filme não chegou. Uma cidade maior que Bacurau, mas onde, quando se ouvem sons de sirene - de polícia ou ambulâncias - comunicadores de um blog local se encarregam de apurar e, em minutos, a população pode receber, via WhatsApp, a informação sobre o incidente. Ao assistir ao filme, essa lembrança me fez unir aquela pequena cidade do sul à fictícia Bacurau e suas redes de comunicação.

$\mathrm{Na}$ premiada obra de Kleber Mendonça, Bacurau, pequena cidade do sertão do nordeste, é atacada por um grupo predador de estrangeiros que praticam violência por esporte. Sem contar com a proteção de forças policiais, e com profundo desprezo por seu prefeito corrupto - símbolos da ausência ou inoperância do poder do Estado -, a cidade acaba por estranhamente "sumir do mapa".

Segundo levantamento do Atlas da Notícia (iniciativa do Instituto para o Desenvolvimento do Jornalismo - Projor, em parceria com a agência de jornalismo de dados Volt Data Lab), em 2018, no Brasil, 15\% da população vivia em municípios sem veículos jornalísticos (não possuem jornais impressos, sites de notícia, emissoras de rádio e de TV). São "desertos de notícias" que, segundo a pesquisa, abrangem pouco mais da metade dos municípios brasileiros. Locais em que vivem 30 milhões de pessoas que, não produzindo ou tendo produzidas notícias sobre si, têm invisibilizadas suas narrativas - suas demandas e seus valores.

Outras comunidades "às margens" não são retratadas nem comunicadas pela visão míope dos media tradicionais, ou são retratadas por perspectivas equivocadas e incompletas. Entre elas, comunidades indígenas, rurais, ou de periferias de grandes cidades, acabam por simplesmente "sumir do mapa" que agenda os debates públicos, informa sobre a realidade e representa os imaginários sociais do país. Não existir nos media também pode significar não constar dos temas relevantes em uma nação que não os vê, ou os vê plenos de estigmas. Para contrapor-se a esse estado de coisas, é que a comunicação popular e alternativa se torna potente munição.

No filme, os habitantes de Bacurau se utilizam de antigas e modernas ferramentas de comunicação para lidar com problemas cotidianos: notícias e avisos são dados pelas redes, inclusive partindo das margens da cidade, informando sobre visitantes que se aproximam, de

${ }^{3}$ BACURAU. Direção de Kleber Mendonça Filho e Juliano Dornelles. São Paulo: Vitrine Filmes, 2019.132 minutos. 
onde se repassa a informação por telefone, alcançando rapidamente o restante da população. Para resolver questões administrativas - não solucionadas pelo representante oficial, o prefeito eleitoreiro - a comunidade faz reuniões, em que decide, com a mediação do líder um professor - o que fazer com alimentos vencidos e remédios inadequados doados pelo governante. A comunicação boca-a-boca funciona durante todo o enredo, através de áudios nos celulares e conversas em grupos menores, providenciando toda uma rede informativa que protege e une a população.

Há, ainda, a figura do repentista, que canta suas impressões sobre os forasteiros que chegam à cidade e provocam desconfiança nos moradores. $\mathrm{O}$ cantador representa a oralidade tradicional das culturas sertanejas, mas também por meio das novas tecnologias, um tablet e um computador, que são usados na escola, é que o professor, em pesquisa com os alunos, acaba por descobrir que Bacurau havia sumido do mapa. Assim, é a partir das formas de comunicação que constroem que seus habitantes logram defender-se tanto das ausências do Estado como do ataque estrangeiro.

\section{Paz em guerra}

A placa de boas-vindas que delimita a chegada à cidade - "Bacurau, $17 \mathrm{~km}$. Se for, vá na paz" - é, em si, um dispositivo que orienta ao visitante, comunicando o que de mais valioso se busca manter naquele local. Mas se aquela população é chamada à batalha, é na guerra que se centra o clímax na narrativa do filme. Uma das cenas finais da sangrenta luta contra os forasteiros acontece no museu da cidade - lugar defendido pelos moradores. Nele, representações do cangaço, feitos valentes do povo do lugar e seus heróis, suas famílias, seu imaginário. Cenário da luta, o museu serve também de esconderijo e arsenal, de onde os guerreiros retiram armas para enfrentar os invasores estrangeiros.

Martín-Barbero (2011) defende a ideia do "museu como instituição indispensável à memória dos povos". Mais que isso, o museu aqui transcende sua função de registro de acontecidos e consolida-se local de luta presente e projeção de futuro, nele imbricando-se elementos e espaços físicos, e memória imaterial, como apoio para ações na construção de realidades concretas, nas lutas cotidianas do povo e na sangrenta luta campal.

Após a derrota dos invasores, a personagem que orienta o trabalho de limpeza do museu pede que o chão seja lavado, mas as marcas das mãos ensanguentadas do inimigo devem ficar na parede - símbolo de uma luta que não deve ser esquecida. O museu se torna "lugar de memória" (NORA, 1993): como monumentos, símbolos e instituições construídas 
para o relembrar, "concretizam-se como espaços importantes para os que viveram os eventos e para os que querem conhecer o passado em uma dinâmica diferente da apresentada por outros meios" (BRIONES, 2015, p. 2), buscando promover cura, fortalecimento e conhecimento social (BRIONES, 2015).

Como lugar de memória, o museu também é processo de comunicação que informa, socializa e contribui na construção do imaginário do povo. Como atitude de seleção, é também pedagogia, uma proposta para o futuro.

Peruzzo (2016) nos lembra de que é preciso pensar comunicação fora dos fluxos tradicionais:

Nós podemos pensar na comunicação popular, comunitária, não só naquela dimensão em que envolvem meios de comunicação, que seria o rádio, o boletim, o vídeo. É tudo isso, mas é mais do que isso: é também a comunicação presencial, a comunicação por meio do diálogo. Comunicação que se dá nos grupos, nas reuniões, no contato interpessoal.

A comunicação popular, nesse sentido, perpassa as formas com que as comunidades se organizam e socializam suas informações, internamente ou para fora delas, sendo “eminentemente educativa", porque "aponta à construção e à mobilização coletiva desde e a partir da qual se conquistam direitos e se aprofundam as lutas sociais" (ELBIRT, 2015, p. 69, tradução nossa).

Assim, como o jornalismo tem se preocupado com o paradoxo da desinformação fruto de um excesso de informação, e com a problemática da "pós-verdade", há que se pensar também no outro extremo: o contexto dos desertos de notícias e regiões negligenciadas por aparatos estatais igualmente desconsiderados pelos veículos noticiosos, "apagados" dos discursos da esfera pública, sem a chance sequer de veicularem suas próprias "verdades". É ali onde, ainda que "sumidas dos mapas", populações encontram brechas em dispositivos midiáticos, e dispositivos em brechas, para mediações positivas em seus cotidianos e militância.

Uranga (2007, p. 3, tradução nossa), quando nos fala de práticas sociais como "experiência de comunicação" e "manifestação do político", as coloca como potenciadoras de mudanças sociais. E uma comunicação para a mudança social deve partir da reconstrução da memória: "do que sucedeu, mas também das rotinas, dos discursos que falam de experiências acumuladas" (URANGA, 2007, p. 14). É desses modos que, por meio de processos de comunicação envolvidos em suas atividades corriqueiras ou estratégias de luta, se busca e se 
faz possível "a transformação dos grupos que se consideram subalternizados" (SAAVEDRA, 2015, p. 88, tradução nossa).

Quando os habitantes de Bacurau se unem para sobreviver ou resistir contra inimigos - o governo negligente e o invasor externo -, eles posicionam-se frente a detentores de poderes de outro modo dominantes na sociedade - dominação que é política, cultural ou econômica - tensionando e contestando tais poderes. E o fazem a partir de atos comunicacionais que "não só favorecem a solidariedade e a organização no bairro, mas que ademais tomam uma posição clara frente a outros atores sociais, ligados aos setores dominantes, e os enfrentam em negociações e conflitos concretos desde a perspectiva dos setores populares" (BORRI ${ }^{4}$, p. 19, tradução nossa), o que caracteriza a comunicação popular. São processos que podem ser pensados, nos termos de Kaplún (2007, p. 313), como mudanças sociais pressionadas "de baixo para cima".

Em seu cotidiano - do boca-a-boca às reuniões comunitárias, do uso das novíssimas tecnologias de informação aos registros da memória simbolizados pelo museu - é por meio desses atos comunicativos que os habitantes de Bacurau se ancoram e mobilizam-se em torno de suas pautas e discussões, a despeito e apesar das negligências e ataques sofridos por parte de administradores e invasores. O repentista, que conta cantando a história local, e o convite dos habitantes para que visitantes conheçam o museu, ilustram que esse povo quer contar-se, contar a si mesmo, ser visto por suas batalhas vencidas que os construíram como povo, e quer contar e construir suas histórias por si mesmos. Movimento que se repete por incontáveis pontos do país, das periferias urbanas a rincões do sertão.

Nesses locais é que a comunicação popular - aquela feita por e para o povo - cumpre função essencial ao amplificar sua voz e a contribuir para que as narrativas visíveis sejam mais plurais e diversas. Junto dos lugares de memória, como dispositivos comunicacionais e pedagógicos, constituem chaves na preservação não só da história, mas do futuro dessas populações.

\section{Referências}

ATLAS DA NOTÍCIA. Disponível em: https://www.atlas.jor.br/. Acesso em: 4 nov. 2019.

\footnotetext{
${ }^{4}$ Extraído do livreto "Barrio Galaxia: Manual de Comunicación Comunitaria", projeto coordenado por Néstor Borri e produzido pelo Programa de Desarrollo de Recursos de Comunicación de Organizaciones Sociales del Centro Nueva Tierra (Buenos Aires). A publicação indica "textos principais, sendo de autoria de Eduardo Balán, que é comunicador popular, mas cada texto não apresenta autoria separadamente.
} 
BORRI, N. (coord.). El barrio como escenario de comunicación. In: GLEZ, P. M. Barrio Galaxia: Manual de Comunicación Comunitaria. 2. ed. Buenos Aires: Centro Nueva Tierra, 2002. Disponível em:

https://www.academia.edu/8984789/Barrio_Galaxia_Manual_de_comunicaci\%C3\%B3n_com unitaria. Acesso em: 17 mar. 2020.

BRIONES, M. C. H. Sítios de consciência, a memória e a comunicação. In:

ELBIRT, A. L. La barrialidad desbordada. Anotaciones sobre los contextos de la intervención en comunicación popular en la ciudad de Salta. In: BURGOS, R. (ed.). Comunicación

popular y alternativa en contextos de frontera: mapeo de actores y experiencias en sectores populares de Salta. Córdoba: Gráfica 29 de Mayo, 2015. p. 51-74. Disponível em https://www.academia.edu/35300758/Comunicacion_popular_y_alternativa. Acesso em 04 nov. 2019.

ENCONTRO NACIONAL DE HISTÓRIA DA MÍDIA, 10., 2015, Porto Alegre. Anais [...]. Associação Brasileira de Pesquisadores de História da Mídia (ALCAR), 2015. Disponível em: http://www.ufrgs.br/alcar/encontros-nacionais-1/encontros-nacionais/10o-encontro-2015/gthistoria-da-midia-alternativa/sitios-de-consciencia-a-memoria-e-a-comunicacao/view. Acesso em: 17 mar. 2020.

KAPLÚN, G. La comunicación comunitaria. In: Díaz Nosty (Dir.). Tendencias '07. Medios de Comunicación: el escenario Iberoamericano. Madrid: Fundación Telefónica; Editorial Ariel, 2007. p. 311-320. Disponível em:

https://www.infoamerica.org/primera/anuario_medios.pdf . Acesso em: 17 mar. 2020.

MARTÍN BARBERO, Culturas/Tecnicidades/Comunicación. Organización de Estados Iberoamericanos - Para la educación, la ciencia y la cultura - Iberoamerica: Unidad cultural en la diversidad. 2011. Disponível em: https://www.oei.es/historico/cultura2/barbero.htm Acesso em: 17 mar. 2020.

NORA, P. Entre memória e história: a problemática dos lugares. Projeto História, São Paulo, n. 10, p. 7-28, 1993. Disponível em: https://revistas.pucsp.br/revph/article/view/12101/8763. Acesso em 04 nov. 2019.

PERUZZO, C. [Entrevista concedida a] Arthur Marchetto e Pedro Zuccolotto. Comunicação popular e comunitária: um panorama brasileiro. Jornal Brasileiro de Ciência da

Comunicação. São Paulo. 13 out. 2016. Disponível em:

http://portal.metodista.br/unesco/jbcc/noticias-jbcc/comunicacao-popular-e-comunitaria-umpanorama-brasileiro. Acesso em: 4 nov. 2019.

SAAVEDRA, M. N. Proceso de conformación de las identidades en el barrio gauchito gil: la incidencia del territorio en relación a las cuestiones de frontera y al desarrollo de prácticas comunicacionales locales. In: BURGOS, R. (ed.). Comunicación popular y alternativa en contextos de frontera: mapeo de actores y experiencias en sectores populares de Salta. Córdoba: Gráfica 29 de Mayo, 2015. p. 75-94. Disponível em: https://www.academia.edu/35300758/Comunicacion_popular_y_alternativa. Acesso em: 4 nov. 2019. 
URANGA, W. Mirar desde la comunicación: una manera de analizar las prácticas sociales, 2007. Disponível em: https://animacionsocioculturalunlz.files.wordpress.com/2014/09/mirardesde-la-comunicacic3b3n-uranga.pdf. Acesso em: 24 mar. 2020.

Submetido em 19 de novembro de 2019.

Aprovado em 9 de março de 2020. 